\title{
Do country-level environmental factors explain cross-national variation in adolescent physical activity? A multilevel study in 29 European countries
}

\author{
Dominic Weinberg $^{1 *}$ D, Gonneke W. J. M. Stevens' ${ }^{1}$ Jens Bucksch², Jo Inchley ${ }^{3,4}$ and Margaretha de Looze
}

\begin{abstract}
Background: Worldwide, roughly $80 \%$ of adolescents fail to meet World Health Organization (WHO) recommendations regarding physical activity, though there is substantial variation in adolescent physical activity prevalence across countries. This study explored whether country-level environmental differences explained cross-national variation in adolescent moderate- to vigorous-intensity physical activity (MVPA) and vigorous-intensity activity (VPA).

Method: Using the data of 138,014 11- to 15-year-olds from 29 European countries in the 2013/2014 Health Behaviour in School-aged Children (HBSC) study, multilevel regression models examined the influence of four types of country-level environmental factors (physical, socio-cultural, economic, and political) on self-reported individual-level physical activity (MVPA and VPA).
\end{abstract}

Results: The environmental variables explained 38\% of country-level variance in MVPA and 81\% of country-level variance in VPA. Lower annual average national temperature, higher community safety, lower average national household income and a weaker physical education policy were significantly associated with more MVPA. Greater urbanisation, lower annual average national temperature, higher adult physical activity and higher average national household income were significantly associated with more VPA.

Conclusions: The findings showed that national differences in the physical, socio-cultural and economic environment were related to adolescent physical activity. They point to potential avenues for future research looking at interactions between individual and environmental factors.

Keywords: Adolescence, Physical activity, Ecological theory, Environmental determinants, International comparison, Europe, Multilevel model, HBSC

\section{Background}

Physical inactivity in adolescence is a critical public health issue [1]. The World Health Organization (WHO) recommends children and adolescents aged 5-17 accumulate at least $60 \mathrm{~min}$ a day of moderate- to vigorous-intensity physical activity (MVPA), and undertake vigorous-intensity physical activities (VPA) at least three times per week [2]. These recommendations are founded on evidence that moderate-intensity physical activity (performed at 3.0-5.9

\footnotetext{
* Correspondence: d.w.weinberg@uu.nl

${ }^{1}$ Department of Interdisciplinary Social Science, Universiteit Utrecht, Heidelberglaan 1, Postbus 80140, 3508, TC, Utrecht, The Netherlands Full list of author information is available at the end of the article
}

times the intensity of rest, e.g. brisk walking, dance, and cycling to school) and VPA (more intense activity, e.g. running, soccer, and swimming laps) are important for shortand long-term health, including metabolic, musculoskeletal, cardiovascular and mental health [3, 4]. Furthermore, physical activity patterns typically track from childhood into adulthood [5], and the continuation of physical exercise throughout adulthood has been found to contribute to cognitive capacity and the prevention of dementia [6,7].

However, levels of inactivity in adolescents and adults are high and estimated to cost $\$ 67.5$ billion worldwide through health-care expenditure and productivity losses [8]. In $2010,84 \%$ of girls and $78 \%$ of boys worldwide

(c) The Author(s). 2019 Open Access This article is distributed under the terms of the Creative Commons Attribution 4.0 International License (http://creativecommons.org/licenses/by/4.0/), which permits unrestricted use, distribution, and reproduction in any medium, provided you give appropriate credit to the original author(s) and the source, provide a link to the Creative Commons license, and indicate if changes were made. The Creative Commons Public Domain Dedication waiver (http://creativecommons.org/publicdomain/zero/1.0/) applies to the data made available in this article, unless otherwise stated. 
(aged 11-17) were insufficiently physically active [9], with older adolescents particularly unlikely to meet recommended targets; MVPA declines by as much as 7\% per year during adolescence, though the trend in VPA is less clear $[10,11]$. Despite recognition of the need for global action, there has been relatively little progress in increasing physical activity since 2010 [7, 12, 13].

Importantly, substantial variation in adolescent physical activity prevalence exists across and within countries $[9,14$, 15], including within Europe [11, 13]. To illustrate, the 2013/2014 Health Behaviour in School-aged Children (HBSC) study found $41 \%$ of 11-year-olds in Finland, but only $13 \%$ of their counterparts in Italy, met WHO guidelines on daily MVPA. Correspondingly, 76\% of Danish 15year-olds, but only $30 \%$ of their Albanian counterparts, participated in VPA outside school for two or more hours per week [16].

International variation can be attributed to differences in the characteristics of individuals within a country, such as adolescent motivations for participation in physical activity [17]. Motivations, and therefore physical activity levels, may be explained by differences in country-level environmental factors [18]. Ecological models emphasise the importance of the environment as a context for physical activity [19]. Empirical research supports this theoretical approach and findings indicate that physical activity behaviour is affected by environmental influences across recreational, transport, household and occupational domains [20]; national differences in these environments might contribute to cross-national variation in adolescent physical activity [21]. The ecological Analysis Grid for Environments Linked to Obesity (ANGELO) framework provides a useful tool for distinguishing four types of environmental factors relevant to physical activity: physical, socio-cultural, economic and political [22]. The framework has been used to understand how cross-national environmental variation facilitates or hinders adult physical activity [23, 24], but has not yet been applied in multilevel analysis with adolescents.

Among adolescents, studies have identified several different characteristics of the physical environment to be important for physical activity. Urbanisation contributes to land-use mix (i.e. where housing is near commercial and institutional destinations, raising neighbourhood walkability [25]); systematic reviews have concluded that facilities for physical activity (e.g. gyms), population density and land-use mix are positive correlates of physical activity in adolescents [26, 27]. Temperature is another important aspect of the physical environment, with extreme conditions making physical activity less appealing [28]. Seasonal effects, with adolescents in many countries more physically active during warmer months, have been widely found, but cross-national analysis shows a more complex relationship between national temperature and physical activity, with less activity in hot countries [29].
The effect of the socio-cultural environment (i.e. attitudes, beliefs and values about physical activity) is better understood at the micro (e.g. home and school) level than at the macro (regional or country) level [30]. Adult physical activity may be associated with adolescent physical activity because adolescents are potentially influenced by the norms of others. However, empirical research on the effect of norms at the national level is inconsistent [31, 32]. Subjective assessments of community safety may also be an important aspect of the socio-cultural environment, for example due to the effect of perceptions on appropriateness of children spending time outdoors and in active transportation $[33,34]$. For older adolescents the evidence of the effect of safety is more mixed [26].

The national economic environment (i.e. wealth and its distribution in the country of residence) has complex cumulative effects on adolescent health [35]. These effects include its impact on material resources that support physical activity (e.g. facilities) and the social consequences of inequality, including increased stress and social disorder [36]. Public health models typically examine national measures of income inequality and income together [37] and international research has found more adolescent MVPA in countries with higher national income and lower income inequality [38]. This effect was found even after controlling for an individual-level measure of wealth inequality, given consistent findings that children from more affluent families are more physically active $[11,13]$.

Finally, the role of the political environment (i.e. legislative and regulatory actions) has been understudied in physical activity research [20], despite its potential contribution to explaining cross-national differences in adolescent physical activity. One systematic review found evidence that policies promoting physical education in school and active transport (i.e. walking or cycling to school) increased physical activity in adolescents [39].

Research findings therefore suggest that all four types of environmental factors may be relevant for understanding international differences in adolescent physical activity [23, 38]. However, there is a scarcity of internationally comparative research testing the relative importance of the different types of environmental factors for adolescent physical activity. It is important to examine the effects of the environment on both MVPA and VPA, given their separate contribution to adolescent health [4], and the need to understand behaviour-specific environmental correlates [40, 41].

To address these gaps in the literature, this study includes eight national environmental factors (two from each of the four types in the ANGELO framework) to investigate whether cross-national differences in these factors explain international variation in both adolescent MVPA and adolescent VPA. We hypothesised that national differences in these environmental factors would explain a substantive amount of the international variation in adolescent physical 
activity. Based on the evidence discussed above, we expected to find higher levels of MVPA and VPA among adolescents living in countries with lower national temperatures, greater urbanisation, higher adult physical activity, higher community safety, higher national income, lower income inequality, and physical education and transport policies that supported physical activity.

\section{Methods \\ Participants}

Individual-level data were obtained from the 2013/2014 Health Behaviour in School-aged Children (HBSC) study [16]. This WHO collaborative cross-national study has investigated the health behaviours, well-being and social environment of adolescents since 1983 by self-report. The 2013/2014 survey collected data from roughly 4500 adolescents in each of 42 countries in Europe, North America, and Israel. Each country or region used cluster sampling, selecting schools and classes to get a representative sample of boys and girls aged 11, 13 and 15. Data collection took place between September 2013 and January 2015, with the majority of countries (22 out of 29) conducting fieldwork between January and June 2014 (p. 239, [16]). All participating countries adhere to a standard international protocol to ensure consistency of measures, sampling and implementation procedures [42]. Appropriate ethical approval for the survey was gained at national level. Adolescents and their parents were given age-appropriate information about the study's approach to confidentiality and anonymity. Participation was voluntary, and passive consent was sought from school administrators, parents and adolescents, according to local human subject requirements.

The present analyses were based on adolescents from 29 of the 42 HBSC countries and regions $(N=149,660) ; 13$ countries were excluded due to missing data on macro-level variables. Adolescents with a missing value for school $(n=68)$ or a missing value for at least one of the individual-level measures described below $(n=11,578)$ were also excluded from the analyses. Adolescents lived in European countries with 'very high' scores on the Human Development Index (HDI > 8), except Bulgaria (HDI = .794) [43]. Data for England, Wales and Scotland, and the French and Flemish regions of Belgium, were analysed separately. Whenever macro-data were not available for these administrative areas, data for the United Kingdom and Belgium were used. (Further mentions in text refer to all macro-level areas as countries.)

\section{Measures}

Individual-level data on age, gender, school, and physical activity (MVPA and VPA) were obtained from the HBSC study. Country-level data on environmental factors were obtained from internationally recognised online sources used by other researchers.

\section{Physical activity}

The HBSC questionnaire defines MVPA as "any activity that increases your heart rate and makes you get out of breath some of the time", and gives examples of such activity, e.g. biking and dancing (examples could be country-specific). MVPA was assessed with the question: "Over the past 7 days, on how many days were you physically active for a total of at least 60 minutes per day? Please add up all the time you spent in physical activity each day." Responses ranged from 0 to 7 days and this measure was treated as a continuous variable. VPA was assessed with the question: "Outside school hours: how many hours a week do you usually exercise in your free time so much that you get out of breath or sweat?" Answers were recoded to form a continuous scale, ranging from 0 (none) to 7.5 (about $7 \mathrm{~h}$ or more). Both items have been found to have reasonable validity and moderate reliability [44].

\section{Physical environment}

Annual average national temperature data were obtained from Weatherbase for 2017 [45]. This website collects international weather data from public domain sources and was used by Lang and colleagues [46]. National temperature was computed by averaging the annual temperature across major cities in each country using at least 10 years of data. We used nationally representative samples from highly urbanised countries, and as such, the temperature of major cities as assessed with the Weatherbase data was expected to approximate the experience of most adolescents. Urbanisation data were obtained from the World Bank DataBank for 2014 [47]. The data, collected and smoothed by United Nations Population Division, contains national estimates of urban population (\% of total) for 2014. Urban population refers to the percentage of people living in urban areas as defined by national statistical offices; Eurostat defines urban areas as clusters of contiguous grid cells of $1 \mathrm{~km}^{2}$ with a density of at least 300 inhabitants per $\mathrm{km}^{2}$ and a minimum population of 5000 [48].

\section{Socio-cultural environment}

Adult physical activity data were obtained from the Global Health Observatory data repository for 2010 [49]. The repository contains national data on insufficient physical activity prevalence in adults. Insufficient physical activity was defined as the percentage of adults aged 18 and over doing fewer than $150 \mathrm{~min}$ of moderate physical activity per week, and was estimated from population-based surveys, sometimes adjusted by WHO (e.g. due to unrepresentative survey coverage) to enable comparison among countries. Data were recoded to assess the percentage of adults engaged in 
sufficient physical activity. Safety data were obtained from the European Social Survey [50]. The cross-national survey asked a representative sample of people aged 15 and over in each country whether they felt safe walking alone in the local area after dark; answer categories were "very safe", "safe", "unsafe", "very unsafe", and "don't know". Post-stratification weights were used to adjust for sampling error, non-response bias and different selection probabilities. For this study, we calculated the percentage of respondents who reported feeling safe or very safe in the most recent survey for which data were available in each country (2008, 2010, 2012 or 2014).

\section{Economic environment}

Average national household income data were obtained from Eurostat for 2014 [51]. The Eurostat database contains national data on adjusted gross disposable income of households per capita in purchasing power standard (an artificial common currency). Adjusted disposable income takes into account transfers in-kind, such as government provided education and health, and has been proposed to be a better indicator of the material well-being of citizens than gross domestic product per capita (GDP) [52]. Income inequality data were obtained from Eurostat for 2014 [53]. The European Union Statistics on Income and Living Conditions (EU-SILC) instrument provides estimates of cross-national standardised Gini indices of equivalised disposable income inequality. The Gini index theoretically ranges from 0 (everyone having equal income) to 100 (one person having all the income).

\section{Political environment}

Physical education policy data were obtained from the Eurydice network for 2011/12 [54]. The network collected data on the required minimum annual taught time (in hours) for physical education as a compulsory subject in full-time education for children aged 11-15. In Belgium (Flanders), Netherlands, England and Wales, despite a requirement for schools to deliver physical education, there was no specified minimum time. Instead, schools were responsible for deciding the number of hours, so these countries were coded as $1 \mathrm{~h}$ to approximate the minimum time required (i.e. just greater than 0). Transport policy data were obtained from the WHO Regional Office for Europe for 2009 [55]. National experts completed questionnaires and recorded the existence of national or subnational schemes promoting active travel to school. Responses were coded as 0 for countries with no such policies and 1 for countries with policies [56].

\section{Data analysis}

Statistical analyses were conducted with Mplus version 7 using the maximum likelihood estimator with robust standard errors [57]. The associations between individual-level physical activity outcomes and country-level variables were tested by fitting three-level linear regression models, which considered individuals to be clustered within schools $(n=5109)$ and within countries $(n=29)$. The individual- and country-level determinants were added to the models using a stepwise approach. Model 1 included individual-level variables only, to assess whether significant variation between countries in physical activity outcomes existed after adjusting for age and gender. The country-level intraclass correlation (ICC) measured the proportion of variance in physical activity attributable to country-level variation. Model 2 included individual-level variables and all country-level variables. We included only significant variables in the final model, Model 3. Due to large number of predictors and the possibility of correlations between them and suppression effects, we adopted a less conservative $\alpha$-level of .1 as a screening criterion for entry into the final model, Model 3, to ensure that all potentially relevant variables were considered in the final model $[58,59]$. For testing the significance of variables in the final model, $\alpha$ was .05 . The model building sequence was followed for MVPA and VPA separately.

\section{Results}

Table 1 shows the descriptive characteristics of the sample, which reveals substantial variance across countries for all outcome and country-level variables. One hundred thirty-eight thousand fourteen adolescents were included in the analysis (mean age 13.6 years old, $51 \%$ female). MVPA averages in 15-year-olds ranged from 3.20 days per week (Italy) to 4.22 days per week (Finland) and VPA averages in 11-year-olds ranged from $1.78 \mathrm{~h}$ per week (Portugal) to $3.90 \mathrm{~h}$ per week (Netherlands). Correlations between the country-level variables are shown in Table 2 . National income positively correlated with urbanisation and safety, and negatively correlated with adult physical activity and income inequality. Income inequality positively correlated with national temperature and negatively correlated with safety (and national income).

Table 3 displays results of MVPA analyses, with models showing that both gender and age were significant individual-level correlates of MVPA, with less MVPA among girls and older adolescents. Model 1 shows significant school- and country-level variance. The residual ICC - i.e. variance attributable to differences at a higher level after controlling for age and gender - was $3.4 \%$ at schoollevel and 2.6\% at country-level. Model 2 included all country-level variables, and national temperature, safety, national income, and physical education policy met the criterion ( $\alpha$-level of .1) for inclusion in the final model. Model 3 shows that when these variables were included in a regression together, lower national temperature, higher safety, lower national income, and a weaker physical 


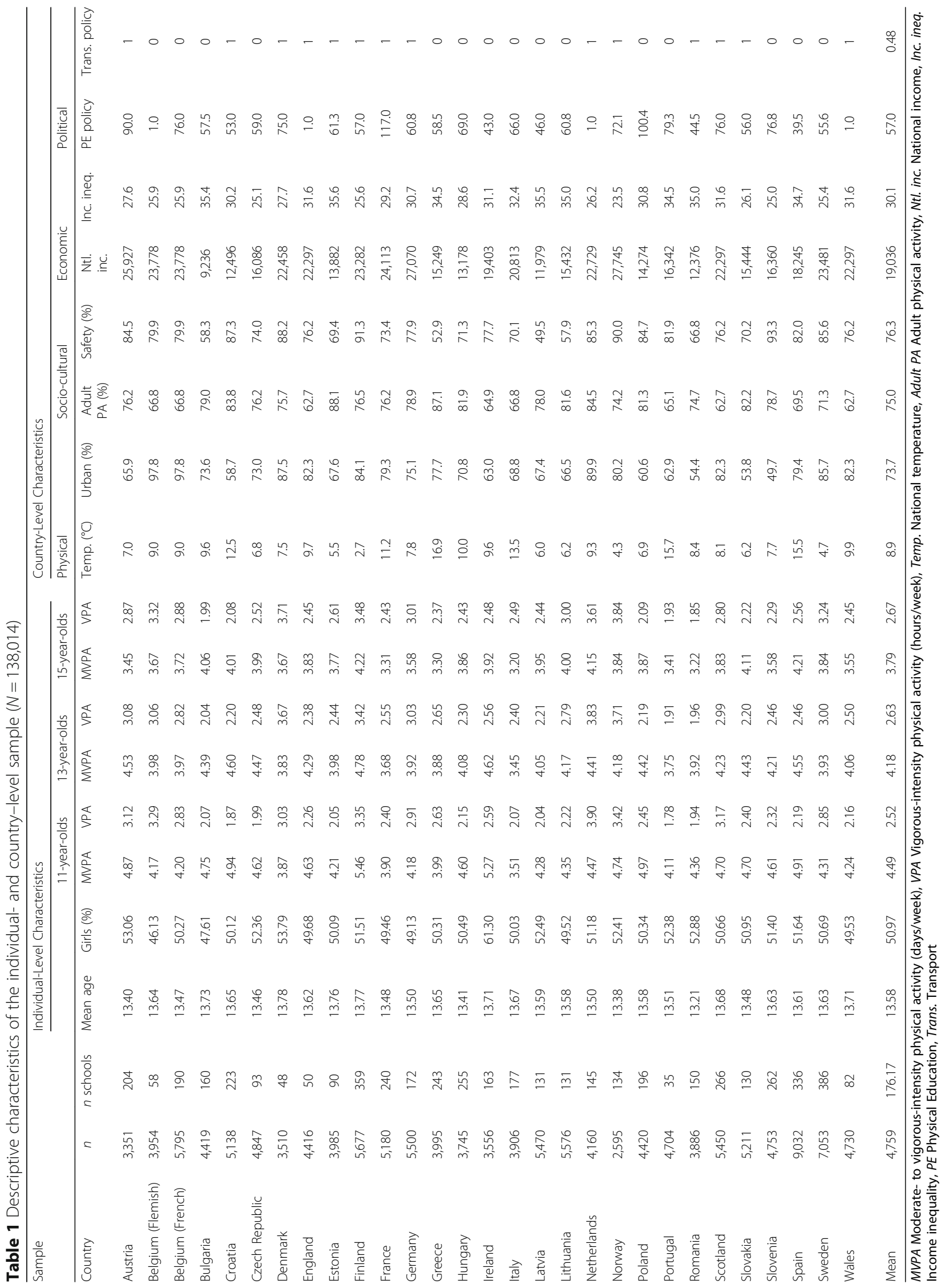


Table 2 Correlations between country-level variables

\begin{tabular}{|c|c|c|c|c|c|c|c|c|}
\hline & Variables & 2 & 3 & 4 & 5 & 6 & 7 & $8^{a}$ \\
\hline \multirow[t]{2}{*}{ Physical } & 1. National temperature & -.03 & -.17 & -.19 & -.20 & $.45^{*}$ & -.07 & -.19 \\
\hline & 2. Urbanisation & & -.34 & .16 & $.61^{* *}$ & -.30 & -.32 & .12 \\
\hline \multirow[t]{2}{*}{ Socio-cultural } & 3. Adult physical activity & & & -.22 & $-.44^{*}$ & .03 & .24 & .05 \\
\hline & 4. Safety & & & & $.54^{* *}$ & $-.67^{* *}$ & .08 & .20 \\
\hline \multirow[t]{2}{*}{ Economic } & 5. National income & & & & & $-.55^{* *}$ & -.04 & .33 \\
\hline & 6. Income inequality & & & & & & -.06 & -.10 \\
\hline \multirow[t]{2}{*}{ Political } & 7. PE policy & & & & & & & -.05 \\
\hline & 8. Transport policy & & & & & & & \\
\hline
\end{tabular}

${ }^{a}$ Transport policy correlation coefficients are Spearman's (other correlations are Pearson). PE Physical Education, ${ }^{*} p<.05,{ }^{* *} p<.01$

education policy were significantly associated (at an $\alpha$-level of .05) with more MVPA. The country-level variables in Model 3 explained $38 \%$ of the total country-level variance.

Table 4 displays results of VPA analyses, with models showing that both gender and age were significant individual-level correlates of VPA, with less VPA found among girls and younger adolescents. Model 1 shows significant school- and country-level variance, with a residual ICC of $3.9 \%$ at school-level and $4.6 \%$ at country-level. Model 2 included all country-level variables, and national temperature, urbanisation, adult physical activity, safety and national income met the criterion for inclusion in the final model. In a model with these five variables, safety was no longer significant $(b=0.007, p=.073)$. Model 3 shows that when the remaining four variables were included in a regression together, lower national temperature, greater urbanisation, more adult physical activity, and higher national income were significantly associated with more VPA. $81 \%$ of the total country-level variance was explained by these four variables.

Sensitivity analyses revealed that the results were robust to changes in the definitions and coding of several variables. The inclusion of an individual-level measure of family socioeconomic status - the Family Affluence Scale (FAS, which was available for all countries except Lithuania and Spain) did not substantially affect the models. An alternative measure of national wealth, a log-transformed measure of GDP, showed an association between higher GDP and more adolescent VPA, but GDP was not associated with MVPA. An alternative measure of annual average national temperature, using World Bank data aggregated across each country (rather than only in major cities), made no

Table 3 Multilevel models for moderate- to- vigorous-intensity physical activity with unstandardised and standardised fixed effects at individual- and country-level $(N=138,014)$

\begin{tabular}{|c|c|c|c|c|c|c|c|c|c|c|}
\hline & & Model 1 & & & Model 2 & & & Model 3 & & \\
\hline & & $b$ (SE) & $p$ & $\beta$ & $b$ (SE) & $p$ & $\beta$ & $b(\mathrm{SE})$ & $p$ & $\beta$ \\
\hline Fixed effects (individual -level) & Intercept & $6.096(0.196)$ & $<.001$ & & $5.649(1.505)$ & $<.001$ & & $6.081(0.357)$ & $<.001$ & \\
\hline & Gender ${ }^{a}$ & $0.619(0.037)$ & $<.001$ & .16 & $0.619(0.037)$ & $<.001$ & .16 & $0.619(0.037)$ & $<.001$ & .16 \\
\hline & Age & $-0.167(0.012)$ & $<.001$ & -.14 & $-0.167(0.012)$ & $<.001$ & -.14 & $-0.167(0.012)$ & $<.001$ & -.14 \\
\hline Fixed effects (country-level) & Ntl. temperature & & & & $-0.039(0.015)$ & .010 & -.39 & $-0.036(0.017)$ & .032 & -.37 \\
\hline & Urbanisation & & & & $0.001(0.007)$ & .923 & .03 & & & \\
\hline & Adult PA & & & & $0.001(0.007)$ & .867 & .03 & & & \\
\hline & Safety & & & & $0.016(0.007)$ & .017 & .54 & $0.014(0.004)$ & .001 & .49 \\
\hline & Ntl. income & & & & $-0.029(0.016)$ & .072 & -.46 & $-0.031(0.009)$ & .001 & -.49 \\
\hline & Income inequality & & & & $0.006(0.019)$ & .732 & .08 & & & \\
\hline & PE policy & & & & $-0.003(0.002)$ & .070 & -.25 & $-0.003(0.001)$ & .024 & -.25 \\
\hline & Transport policy & & & & $-0.039(0.138)$ & .778 & -.06 & & & \\
\hline Variance components & Individual-level & $3.776(0.057)$ & $<.001$ & & $3.776(0.057)$ & $<.001$ & & $3.776(0.057)$ & $<.001$ & \\
\hline & School-level & $0.137(0.013)$ & $<.001$ & & $0.137(0.013)$ & $<.001$ & & $0.137(0.014)$ & $<.001$ & \\
\hline & Country-level ${ }^{b}$ & $0.106(0.026)$ & $<.001$ & & $0.066(0.014)$ & $<.001$ & & $0.066(0.015)$ & $<.001$ & \\
\hline
\end{tabular}

Ntl. National, PA Physical Activity, PE Physical Education, National income divided by 1000 for interpretability of $b$ values

${ }^{a}$ Female is reference group.

${ }^{\mathrm{b}}$ Explained country-level variance $=(106-.066) / .106=.38$

$\mathrm{p}<.05$ are set in bold 
Table 4 Multilevel models for vigorous-intensity physical activity with unstandardised and standardised fixed effects at individualand country-level $(N=138,014)$

\begin{tabular}{|c|c|c|c|c|c|c|c|c|c|c|}
\hline & & Model 1 & & & Model 2 & & & Model 3 & & \\
\hline & & $b(\mathrm{SE})$ & $p$ & $\beta$ & $b(\mathrm{SE})$ & $p$ & $\beta$ & $b(\mathrm{SE})$ & $p$ & $\beta$ \\
\hline \multirow[t]{3}{*}{ Fixed effects (individual -level) } & Intercept & $1.709(0.218)$ & $<.001$ & & $-2.745(1.144)$ & .415 & & $-1.992(0.961)$ & 0.011 & \\
\hline & Gender $^{a}$ & $0.738(0.049)$ & $<.001$ & .16 & $0.738(0.049)$ & $<.001$ & .16 & $0.738(0.049)$ & $<.001$ & .16 \\
\hline & Age & $0.039(0.014)$ & .005 & .03 & $0.039(0.014)$ & .005 & .03 & $0.039(0.014)$ & 0.005 & .03 \\
\hline \multirow[t]{8}{*}{ Fixed effects (country-level) } & Ntl. temperature & & & & $-0.035(0.011)$ & .002 & -.23 & $-0.034(0.010)$ & .001 & -.23 \\
\hline & Urbanisation & & & & $0.013(0.005)$ & .004 & .32 & $0.015(0.004)$ & $<.001$ & .36 \\
\hline & Adult PA & & & & $0.028(0.010)$ & .005 & .42 & $0.023(0.009)$ & .009 & .34 \\
\hline & Safety & & & & $0.008(0.004)$ & .037 & .17 & & & \\
\hline & Ntl. income & & & & $0.066(0.016)$ & $<.001$ & .67 & $0.064(0.012)$ & $<.001$ & .65 \\
\hline & Income inequality & & & & $0.004(0.013)$ & .767 & .03 & & & \\
\hline & PE policy & & & & $-0.003(0.002)$ & .247 & -.14 & & & \\
\hline & Transport policy & & & & $-0.115(0.109)$ & .288 & -.12 & & & \\
\hline \multirow[t]{3}{*}{ Variance components } & Individual-level & $4.923(0.118)$ & $<.001$ & & $4.923(0.118)$ & $<.001$ & & $4.923(0.118)$ & $<.001$ & \\
\hline & School-level & $0.208(0.025)$ & $<.001$ & & $0.207(0.025)$ & $<.001$ & & $0.207(0.025)$ & $<.001$ & \\
\hline & Country-level $^{b}$ & $0.248(0.058)$ & $<.001$ & & $0.038(0.009)$ & $<.001$ & & $0.046(0.013)$ & $<.001$ & \\
\hline
\end{tabular}

Ntl. National, PA Physical Activity, PE Physical Education. National income divided by 1000 for interpretability of $b$ values

${ }^{a}$ Female is reference group

${ }^{\mathrm{b}}$ Explained country-level variance $=(.248-.046) / .248=.81$

$\mathrm{p}<.05$ are set in bold

substantial difference to results. Likewise, transport policy remained an insignificant predictor when coded as 0 for "no policy", 1 for "policy stated but only partially implemented or enforced" and 2 for "policy entirely implemented and enforced".

\section{Discussion}

This study shows that national differences in the physical, socio-cultural, economic and policy environment were associated with individual differences in adolescent physical activity. Characteristics of the national environment explained a large amount of the international variation: $81 \%$ of country-level variance in VPA and $38 \%$ of country-level variance in MVPA. Adolescents did more MVPA in countries with lower annual average national temperatures, higher perceptions of community safety, lower average national income and weaker physical education policies. More adolescent VPA took place where there was a lower annual average national temperature, a higher percentage of urban areas, more adult physical activity and a higher national income. The findings show that combinations of characteristics from different environment types best explained both MVPA (physical, socio-cultural, economic and policy) and VPA (physical, socio-cultural and economic), and as such indicate the usefulness of the ANGELO framework. Furthermore, different environmental factors were associated with MVPA and VPA, showing a different underlying explanatory pattern for the two behaviours.
Both physical environment measures were associated with physical activity. There was more adolescent MVPA and VPA in countries with lower national temperatures, an association also found for adults [24]. Another study looking at adolescent physical activity across countries also found evidence that, while activity levels are higher during warmer months in many countries, physical activity reduces once mean temperature reaches above $20^{\circ} \mathrm{C}$ [29]. Evidence of more VPA (but not MVPA) in more urbanised countries suggests that facilities may be important for vigorous exercise but not so relevant for everyday activity [60], consistent with previous findings (e.g., [61]).

This interpretation of the results for urbanisation, may also support the unexpected findings for national income, with higher national income associated with more VPA, but lower national income associated with more MVPA. The latter result contrasts with analysis of 2002, 2006 and 2010 HBSC data, which found increases in gross national income (GNI) were related to more MVPA [38]. Sensitivity analysis revealed that GDP (which was more closely correlated with GNI than average national household income) was not associated with MVPA. Thus, it seems likely that average national household income, which is considered a better measure of material living standards than GDP [52], captures something significantly different than either GDP or GNI. It is possible that higher national income encourages engagement in organised sport and exercise, contributing to VPA, but may also encourage 
motor vehicle usage for daily travel while discouraging MVPA (i.e. cycling and walking).

Income inequality was not associated with MVPA or VPA. Our findings suggest that previous evidence of links between income inequality and physical activity could be due to the correlations between income inequality and national temperature and safety (MVPA) and urbanisation (VPA) [38]. At the country-level, higher family affluence has been associated with more physical activity (the finding is stronger for VPA than MVPA [13]), but in this study of country-level factors, controlling for individual-level family affluence did not substantially affect the model.

Concerning the socio-cultural environment, there was more adolescent MVPA and VPA in countries perceived to be safer, although the association between VPA and safety was no longer significant in the final model. Findings that community safety perceptions aggregated at the national level were related to physical activity supports evidence of links between parental perceptions of neighbourhood safety and their children's physical activity [62]. These findings suggest that MVPA may involve higher levels of independent mobility where safety plays an important role (e.g., [63]), whereas VPA, which is more likely to take place in the context of supervised sport or exercise, is less dependent on perceptions of safety. The national level of adult physical activity was significantly associated with VPA but not with MVPA. Adolescents may benefit from a culture of active adults which encourages young people to be involved in sport and exercise $[31,32]$. The lack of findings for MVPA accords with the evidence found in reviews of physical activity correlates which show inconsistent evidence of older family members' influence on individual physical activity [20, 27].

Countries with strong physical education policies (i.e., a greater required minimum annual taught time for physical education) were unexpectedly likely to have lower adolescent MVPA. Strong policies may be a legislative response to low levels of physical activity and may be in the process of implementation. Alternatively, implementation of policies may be suboptimal, with actual practice deviating from official policy [7]. The lack of an effect of physical education policy on VPA may be due to the measure of VPA, which measures exercise outside school hours. The impact of transport policy may not be effectively evaluated using a measure of single policy item. A combination of physical activity-enhancing policies in urban planning, transport, infrastructure and education domains may be necessary to create an environment for more physical activity [7]. Even in just one domain an accumulation of policies and facilities can have a greater effect on physical activity than policy alone [64]. Measures that capture the broader policy agenda, such as a 'global matrix' of internationally comparable indicators of the physical activity environment in adolescence, may be useful for further analyses [12]. Transport policies at the national level may be quite independent from those at the regional or even school level, which may be more influential [65].

\section{Strengths and limitations}

Some limitations of the study should be considered. Firstly, causal relationships between the environment and physical activity cannot be confirmed using such cross-sectional research. However, individual physical activity is unlikely to explain environmental factors such as national temperature, urbanisation or national income. Either these environmental factors have a causal effect or there are confounders which cause both outcome and predictor. Combining these findings with those of longitudinal and experimental research would enable researchers to come to firmer conclusions about causality [66, 67]. Secondly, the results may not be generalisable beyond higher-income European countries. Effects of countrylevel factors could be even stronger with a more diverse sample of countries, although environmental impacts on physical activity differ between higher- and lower-income countries [20,46]. Thirdly, with data from only 29 countries included, the final models should be interpreted with caution. Significant correlations between country-level determinants might have left the study with insufficient power to determine associations. However, without high-quality, contemporaneous, comparable data for many countries it is difficult to study many national environmental effects [68].

Fourthly, assumptions about country-level indicators may have affected the stability of the results, though these assumptions were necessary to include a reasonable sample of countries. The measurement of safety was carried out in different countries in different years. The measure of income inequality could have included some uncertainty, given the poor comparability of international data [69]. The measurement of transport policy was reliant on the judgement of individual experts and was a categorical dummy variable, which may have limited the power to detect effects from this indicator. Future studies should consider including explanatory variables at the region- or school-level (including temperature, assessments of community safety and policy measures), because national indicators may underestimate the effect of local environmental influences. Measures of annual average temperature also do not capture whether there are substantial or small seasonal effects that cause temperatures to fluctuate throughout the year, which may affect adolescent physical activity [28]. The data in this study were collected at different times of the year in different countries and therefore may be subject to some seasonal effects. Finally, the reliability of self-reported physical activity data can depend on cultural 
and socio-demographic factors [70]. Further research using different measures would add to the evidence base.

This study's unique strength is its evaluation of models with multiple national predictors and comparable individual-level data from 29 countries. The results suggest that researchers studying country-level influences on physical activity should consider including different types of environmental factors into their models and avoid assumptions that physical, economic, socio-cultural or political factors alone explain international differences in MVPA and VPA. Inconsistent findings regarding environmental correlates (see $[26,31]$ ) may be partly explained by the presence (or absence) of other relevant environmental covariates in researchers' models.

\section{Conclusion}

Despite considerable cross-national variability in adolescent physical activity, explanations of this variability are scarce. Previous research examining the role of environmental factors has given limited attention to the relative importance of different types of environmental factors, so this study examined eight different factors in a single design. The findings that physical, socio-cultural, economic and political environment factors are all related to physical activity provide support for ecological theory and emphasise the importance of taking different environmental factors into account simultaneously. Future research should acknowledge the conceptual difference between MVPA and VPA, given they are associated with different environmental factors. Intervention planning must therefore consider how environmental strategies affect both moderate and vigorous physical activity. Notwithstanding the effects we found on the country-level, effects on the individual level - where most of the variation in adolescent physical activity takes place - are much stronger. However, from a scientific and public health perspective it is important to know how the country-level variance can be explained. Further studies could examine mechanisms through which country-level factors affect adolescent physical activity or look more closely at interactions between individual and environmental factors, which might shed light on cross- national gender, age and socio-economic differences [16]. This may help increase physical activity in groups where it is low, such as girls. With low levels of physical activity in adolescents worldwide, it is vital that researchers continue to investigate the determinants of both daily physical activity and vigorous exercise.

\section{Additional file}

Additional file 1: Information on ethical approvals in the HBSC study 2009/2010, provided by the principal investigator of each country. (DOCX $16 \mathrm{~kb})$

\section{Abbreviations}

ANGELO: Analysis Grid for Environments Linked to Obesity; EU-

SILC: European Union Statistics on Income and Living Conditions;

FAS: Family Affluence Scale; GDP: Gross domestic product per capita;

GNI: Gross National Income; HBSC: Health Behaviour in School-aged Children; HDI: Human Development Index; ICC: Intraclass correlation; MVPA: Moderateto vigorous-intensity physical activity; VPA: Vigorous-intensity physical activity; WHO: World Health Organization

\section{Acknowledgements}

Not applicable.

Funding

Not applicable. No funding sources were involved in this paper.

\section{Availability of data and materials}

Individual-level data on age, gender, school, and physical activity (MVPA and VPA) were obtained from the HBSC 2013-14 study. These data are publicly available from the HBSC Data Management Centre, http://www.uib.no/en/ hbscdata. Raw country-level data on environmental factors were obtained from publicly accessible internationally-recognised online sources. The data transformation used to convert this raw data into the analysed data is set out in the methods section, and the analysed country-level is included in Table 1. Raw data files and further details of the transformation are available on request.

\section{Authors' contributions}

DW was responsible for the overall conception, design and writing of this manuscript. GS contributed to the design of the study and interpretation of data. GS, JB, Jl, and MdL helped to draft the manuscript and revised the manuscript for important intellectual content. All authors read and approved the final manuscript.

\section{Ethics approval and consent to participate}

Data collection took place in multiple countries and appropriate ethical approval and consent was gained in all countries and regions. The HBSC Study Protocol [42] sets out the requirements for each country. Information on the ethics committees and the institutes to which they belong to is available for those countries where ethical approval was necessary (Additional file 1).

Consent for publication

Not applicable.

Competing interests

The authors declare that they have no competing interests.

\section{Publisher's Note}

Springer Nature remains neutral with regard to jurisdictional claims in published maps and institutional affiliations.

\section{Author details}

${ }^{1}$ Department of Interdisciplinary Social Science, Universiteit Utrecht, Heidelberglaan 1, Postbus 80140, 3508, TC, Utrecht, The Netherlands. ${ }^{2}$ Fakultät III - Studiengang Prävention und Gesundheitsförderung, Pädagogische Hochschule Heidelberg, Postfach 1042 40, 69032 Heidelberg, Germany. ${ }^{3}$ Child and Adolescent Health Research Unit, School of Medicine, Medical \& Biological Sciences, University of St Andrews, North Haugh, St Andrews, Fife KY16 9TF, UK. ${ }^{4}$ MRC/CSO Social and Public Health Sciences Unit, University of Glasgow, Top floor, 200 Renfield Street, Glasgow G2 3AX, UK.

Received: 28 August 2018 Accepted: 29 April 2019

Published online: 03 June 2019

References

1. Kohl HW, Craig CL, Lambert EV, Inoue S, Alkandari JR, Leetongin G, et al. The pandemic of physical inactivity: global action for public health. Lancet. 2012;380:294-305 
2. WHO (World Health Organization). Global recommendations on physical activity for health. Geneva: WHO; 2010. http://www.who.int/ dietphysicalactivity/publications/9789241599979/en/. Accessed 21 Dec 2016

3. Janssen I, LeBlanc AG. Systematic review of the health benefits of physical activity and fitness in school-aged children and youth. Int J Behav Nutr Phys Act. 2010;7:40.

4. Poitras VJ, Gray CE, Borghese MM, Carson V, Chaput J-P, Janssen I, et al. Systematic review of the relationships between objectively measured physical activity and health indicators in school-aged children and youth. Appl Physiol Nutr Metab. 2016;41:S197-239.

5. Dobbins M, Husson H, DeCorby K, LaRocca RL. School-based physical activity programs for promoting physical activity and fitness in children and adolescents aged 6 to 18. Cochrane Database Syst Rev. 2013;2:CD007651.

6. Reiner M, Niermann C, Jekauc D, Woll A. Long-term health benefits of physical activity - a systematic review of longitudinal studies. BMC Public Health. 2013;13:813.

7. Sallis JF, Bull F, Guthold R, Heath GW, Inoue S, Kelly P, et al. Progress in physical activity over the Olympic quadrennium. Lancet. 2016;388:1325-36.

8. Ding D, Lawson KD, Kolbe-Alexander TL, Finkelstein EA, Katzmarzyk PT, van Mechelen W, et al. The economic burden of physical inactivity: a global analysis of major non-communicable diseases. Lancet. 2016;388:1311-24.

9. WHO (World Health Organization). Global status report on noncommunicable diseases 2014. Geneva: WHO; 2014. http://www.who.int/ nmh/publications/ncd_report2010/en/. Accessed 27 Jan 2017

10. Dumith SC, Gigante DP, Domingues MR, Kohl HW. Physical activity change during adolescence: a systematic review and a pooled analysis. Int J Epidemiol. 2011;40:685-98.

11. Kalman M, Inchley J, Sigmundova D, lannotti RJ, Tynjälä JA, Hamrik Z, et al. Secular trends in moderate-to-vigorous physical activity in 32 countries from 2002 to 2010: a cross-national perspective. Eur J Pub Health. 2015;25:37-40.

12. Tremblay MS, Barnes JD, González SA, Katzmarzyk PT, Onywera VO, Reilly JJ, et al. Global matrix 2.0: report card grades on the physical activity of children and youth comparing 38 countries. J Phys Act Health. 2016;13:S343-66.

13. Inchley J, Currie D, Jewell J, Breda J, Barnekow V, Bucksch J, et al. Adolescent obesity and related behaviours: trends and inequalities in the WHO European region 2002-2014: observations from the health behaviour in school-aged children (HBSC) WHO collaborative cross-national study. Copenhagen: WHO Regional Office for Europe; 2017. http://www.euro.who. int/en/health-topics/disease-prevention/nutrition/publications/2017/ adolescent-obesity-and-related-behaviours-trends-and-inequalities-in-thewho-european-region,-20022014. Accessed 7 May 2019.

14. Sisson SB, Katzmarzyk PT. International prevalence of physical activity in youth and adults. Obes Rev. 2008;9:606-14.

15. Van Hecke L, Loyen A, Verloigne M, van der Ploeg HP, Lakerveld J, Brug J, et al. Variation in population levels of physical activity in European children and adolescents according to cross-European studies: a systematic literature review within DEDIPAC. Int J Behav Nutr Phys Act. 2016;13:70.

16. Inchley J, Currie D, Young T, Samdal O, Torsheim T, Augustson L, et al. Growing up unequal: gender and socioeconomic differences in young people's health and well-being: Health Behaviour in School-aged Children (HBSC) study: international report from the 2013/2014 survey. Copenhagen: WHO Regional Office for Europe; 2016. http://www.euro.who.int/en/ publications/abstracts/growing-up-unequal.-hbsc-2016-study-20132014survey. Accessed Jun 252018

17. lannotti RJ, Chen R, Kololo H, Petronyte G, Haug E, Roberts C. Motivations for adolescent participation in leisure-time physical activity: international differences. J Phy Act Health. 2013;10:106-14.

18. Diez Roux AV. A glossary for multilevel analysis. J Epidemiol Community Health. 2002:56:588-94

19. Sallis JF, Cervero RB, Ascher W, Henderson KA, Kraft MK, Kerr J. An ecological approach to creating active living communities. Annu Rev Public Health. 2006;27:297-322.

20. Bauman AE, Reis RS, Sallis JF, Wells JC, Loos RJ, Martin BW. Correlates of physical activity: why are some people physically active and others not? Lancet. 2012;380:258-71.

21. Ding D, Adams MA, Sallis JF, Norman GJ, Hovell MF, Chambers CD, et al. Perceived neighborhood environment and physical activity in 11 countries: do associations differ by country? Int J Behav Nutr Phys Act. 2013;10:57.

22. Swinburn B, Egger G, Raza F. Dissecting obesogenic environments: the development and application of a framework for identifying and prioritizing environmental interventions for obesity. Prev Med. 1999;29:563-70.
23. Cameron AJ, Van Stralen MM, Kunst AE, Te Velde SJ, Van Lenthe FJ, Salmon $J$, et al. Macroenvironmental factors including GDP per capita and physical activity in Europe. Med Sci Sports Exerc. 2013;45:278-85.

24. Bosdriesz JR, Witvliet MI, Visscher TL, Kunst AE. The influence of the macroenvironment on physical activity: a multilevel analysis of 38 countries worldwide. Int J Behav Nutr Phys Act. 2012;9:110.

25. Cavill N, Kahlmeier S, Racioppi F. Physical Activity and Health in Europe: Evidence for Action. Copenhagen: WHO Regional Office for Europe; 2006. http://www.euro.who.int/en/publications/abstracts/physical-activity-andhealth-in-europe-evidence-for-action. Accessed Jun 252018

26. Ding D, Sallis JF, Kerr J, Lee S, Rosenberg DE. Neighborhood environment and physical activity among youth: a review. Am J Prev Med. 2011:41:442-55.

27. Martins J, Marques A, Peralta M, Palmeira A, da Costa FC. Correlates of physical activity in young people: a narrative review of reviews. Implications for physica education based on a socio-ecological approach. Retos. 2017;31:292-9.

28. Tucker P, Gilliland J. The effect of season and weather on physical activity: a systematic review. Public Health. 2007;121:909-22.

29. Harrison F, Goodman A, van Sluiis EMF, Andersen LB, Cardon G, Davey R, et al. Weather and children's physical activity; how and why do relationships vary between countries? Int J Behav Nutr Phys Act. 2017;14:74.

30. Ferreira I, Van Der Horst K, Wendel-Vos W, Kremers S, Van Lenthe FJ, Brug J. Environmental correlates of physical activity in youth - a review and update. Obes Rev. 2007;8:129-54.

31. Sterdt E, Liersch $S$, Walter U. Correlates of physical activity of children and adolescents: a systematic review of reviews. Health Educ J. 2013;73:72-89.

32. Draper CE, Grobler L, Micklesfield LK, Norris SA. Impact of social norms and social support on diet, physical activity and sedentary behaviour of adolescents: a scoping review. Child Care Health Dev. 2015;41:654-67.

33. D'Haese S, Vanwolleghem G, Hinckson E, De Bourdeaudhuij I, Deforche B, Van Dyck $D$, et al. Cross-continental comparison of the association between the physical environment and active transportation in children: a systematic review. Int J Behav Nutr Phys Act. 2015;12:145.

34. Galaviz Kl, Zytnick D, Kegler MC, Cunningham SA. Parental perception of neighborhood safety and children's physical activity. J Phy Act Health. 2016; 13:1110-6.

35. Viner RM, Ozer EM, Denny S, Marmot M, Resnick M, Fatusi A, et al. Adolescence and the social determinants of health. Lancet. 2012;379:1641-52.

36. Elgar FJ, Currie C. Early-life exposure to income inequality and adolescent health and well-being: evidence from the health behaviour in school-aged children study. Florence: UNICEF Office of Research; 2016. https://www. unicef-irc.org/publications/pdf/IWP_2016_07.pdf. Accessed 19 Sept 2016

37. Pickett W, Molcho M, Elgar FJ, Brooks F, de Looze M, Rathmann K, et al. Trends and socioeconomic correlates of adolescent physical fighting in 30 countries. Pediatr. 2013;131:e18-26.

38. Elgar FJ, Pförtner T-K, Moor I, De Clercq B, Stevens GWJM, Currie C. Socioeconomic inequalities in adolescent health 2002-2010: a time-series analysis of 34 countries participating in the health behaviour in school-aged children study. Lancet. 2015;385:2088-95.

39. Pate RR, Trilk JL, Byun W, Wang J. Policies to increase physical activity in children and youth. J Exerc Sci Fit. 2011;9:1-14.

40. Edwardson $\mathrm{CL}$, Gorely T. Parental influences on different types and intensities of physical activity in youth: a systematic review. Psychol Sport Exerc. 2010;11:522-35.

41. Giles-Corti B, Timperio A, Bull F, Pikora T. Understanding physical activity environmental correlates: increased specificity for ecological models. Exerc Sport Sci Rev. 2005;33:175.

42. Currie C, Inchley J, Molcho M, Lenzi M, Veselska Z, Wild F, editors. Health Behaviour in School-aged Children (HBSC) Study Protocol: background, methodology and mandatory items for the 2013/14 survey. St Andrews: CAHRU; 2014. http://www.hbsc.org/methods/index.html. Accessed 22 Feb 2018

43. United Nations Development Programme. Human development index and its components. 2016. http://hdr.undp.org/en/composite/HDI. Accessed 6 May 2017.

44. Biddle SJ, Gorely T, Pearson N, Bull FC. An assessment of self-reported physical activity instruments in young people for population surveillance: project ALPHA. Int J Behav Nutr Phys Act. 2011;8:1.

45. Weatherbase. Europe weather averages. 2017. http://www.weatherbase.com/ weather/country.php3?r=EUR\&regionname=Europe. Accessed 6 May 2017.

46. Lang JJ, Tremblay MS, Léger L, Olds T, Tomkinson GR. International variability in $20 \mathrm{~m}$ shuttle run performance in children and youth: who are 
the fittest from a 50-country comparison? A systematic literature review with pooling of aggregate results. Br J Sports Med. 2018;52:276.

47. World Bank. World development indicators (DataBank). 2014. http:// databank.worldbank.org/data/reports.aspx?source=2\&series=SP.URB.TOTL.IN. ZS\&country=. Accessed 6 May 2017

48. Eurostat. Glossary: urban cluster - statistics explained. 2015. http://ec.europa. eu/eurostat/statistics-explained/index.php/Glossary:Urban_cluster. Accessed 6 May 2017.

49. WHO (World Health Organization). Global Health Observatory data repository: prevalence of insufficient physical activity among adults - data by country. WHO. 2015. http://apps.who.int/gho/data/view.main.2463?lang= en. Accessed 6 May 2017.

50. Norwegian Social Science Data Services. European Social Survey Data webview. 2016. http://nesstar.ess.nsd.uib.no/webview/. Accessed 6 May 2017.

51. Eurostat. Adjusted gross disposable income of households per capita in PPS (tec00113). 2017. http://ec.europa.eu/eurostat/web/products-datasets/-/ tec00113. Accessed 7 May 2017.

52. Stiglitz JE, Sen AK, Fitoussi J-P. Report by the commission on the measurement of economic performance and social Progress. Paris: Insee; 2009. https:/www.insee.fr/fr/statistiques/fichier/2550927/stiglitz-rapportfrancais.pdf. Accessed 7 May 2017

53. Eurostat. Gini coefficient of equivalised disposable income - EU-SILC survey (ilc_di12). 2017. http://ec.europa.eu/eurostat/web/products-datasets/-ilc_ di12. Accessed 7 May 2017.

54. European Commission, EACEA, Eurydice. Physical education and sport at school in Europe. Luxembourg: Publications Office of the European Commission; 2013. http://bookshop.europa.eu/uri?target=EUB:NOTICE: EC3113672:EN:HTML. Accessed 7 May 2017

55. WHO Regional Office for Europe. Country profiles on nutrition, physical activity and obesity. 2013. http://www.euro.who.int/en/health-topics/ disease-prevention/nutrition/country-work. Accessed 7 May 2017.

56. WHO Regional Office for Europe. Methodology and summary: country profiles on nutrition, physical activity and obesity in the 53 WHO European region member states. Copenhagen: WHO regional Office for Europe; 2013. http://www.euro.who.int/_data/assets/pdf_file/0004/243337/Summarydocument-53-MS-country-profile.pdf. Accessed 6 May 2017

57. Muthén LK, Muthén BO. Mplus User's guide. Seventh. Los Angeles: Muthén \& Muthén; 1998. https://www.statmodel.com/download/usersguide/ Mplus\%20user\%20guide\%20Ver_7_r3_web.pdf. Accessed 7 May 2019.

58. Bendel RB, Afifi AA. Comparison of stopping rules in forward "stepwise" regression. J Am Stat Assoc. 1977;72:46.

59. Menard S. Applied logistic regression analysis. Thousand Oaks: SAGE; 2002.

60. King AC, Stokols D, Talen E, Brassington GS, Killingsworth R. Theoretical approaches to the promotion of physical activity: forging a transdisciplinary paradigm. Am J Prev Med. 2002;23:15-25.

61. Niclasen B, Petzold M, Schnohr CW. The association between high recreational physical activity and physical activity as a part of daily living in adolescents and availability of local indoor sports facilities and sports clubs. Scand J Soc Med. 2012;40:614-20.

62. Duke NN, Borowsky IW, Pettingell SL. Parent perceptions of neighborhood: relationships with US youth physical activity and weight status. Matern Child Health J. 2012:16:149-57.

63. Schoeppe S, Duncan MJ, Badland HM, Alley S, Williams S, Rebar AL, et al. Socio-demographic factors and neighbourhood social cohesion influence adults' willingness to grant children greater independent mobility: a crosssectional study. BMC Public Health. 2015;15:690.

64. Nichol ME, Pickett W, Janssen I. Associations between school recreational environments and physical activity. J Sch Health. 2009;79:247-54.

65. Haug E, Torsheim T, Samdal O. Local school policies increase physical activity in Norwegian secondary schools. Health Promot Int. 2010;25:63-72.

66. Atkin AJ, van Sluijs EMF, Dollman J, Taylor WC, Stanley RM. Identifying correlates and determinants of physical activity in youth: how can we advance the field? Prev Med. 2016;87:167-9.

67. Uijtdewilligen L, Nauta J, Singh AS, van Mechelen W, Twisk JWR, van der HK, et al. Determinants of physical activity and sedentary behaviour in young people: a review and quality synthesis of prospective studies. $\mathrm{Br} J$ Sports Med. 2011:45:896-905.

68. Alexander D, Rigby MJ, Di Mattia P, Zscheppang A. Challenges in finding and measuring behavioural determinants of childhood obesity in Europe. J Public Health. 2015;23:87-94.
69. Solt F. The standardized world income inequality databas. Soc Sci Q. 2016; 97:1267-81.

70. Cerin E, Cain KL, Oyeyemi AL, Owen N, Conway TL, Cochrane T, et al. Correlates of agreement between accelerometry and self-reported physical activity. Med Sci Sports Exerc. 2016;48:1075-84.
Ready to submit your research? Choose BMC and benefit from:

- fast, convenient online submission

- thorough peer review by experienced researchers in your field

- rapid publication on acceptance

- support for research data, including large and complex data types

- gold Open Access which fosters wider collaboration and increased citations

- maximum visibility for your research: over $100 \mathrm{M}$ website views per year

At BMC, research is always in progress.

Learn more biomedcentral.com/submissions 